\title{
Current and Prospective Targets of Pharmacologic Treatment of Hereditary Angioedema Types 1 and 2
}

\author{
Lauré M. Fijen ${ }^{1}$ (D) $\cdot$ Konrad Bork $^{2}$ (D) Danny M. Cohn ${ }^{1}$ (D)
}

Accepted: 1 January 2021 / Published online: 9 January 2021

(C) The Author(s) 2021

\begin{abstract}
Hereditary angioedema (HAE) is a rare disease that causes episodic attacks of subcutaneous and submucosal edema, which can be painful, incapacitating, and potentially fatal. These attacks are mediated by excessive bradykinin production, as a result of uncontrolled activation of the plasma kallikrein/kinin system, which is caused by a $\mathrm{C} 1$ esterase inhibitor deficiency or dysfunction in HAE types 1 and 2, respectively. For many years, treatment options were limited to therapies with substantial adverse effects, insufficient efficacy, or difficult routes of administration. Increased insights in the pathophysiology of HAE have paved the way for the development of new therapies with fewer side effects. In the last two decades, several targeted novel therapeutic strategies for HAE have been developed, for both long-term prophylaxis and on demand treatment of acute attacks. This article reviews the advances in the development of more effective and convenient treatment options for HAE and their anticipated effects on morbidity, mortality, and quality of life. The emergence of these improved treatment options will presumably change current HAE guidelines, but adherence to these recommendations may become restricted by high treatment costs. It will therefore be essential to determine the indications and identify the patients that will benefit most from these newest treatment generations. Ultimately, current preclinical research into gene therapies may eventually lead the way towards curative treatment options for HAE. In conclusion, an increasing shift towards the use of highly effective long-term prophylaxis is anticipated, which should drastically abate the burden on patients with hereditary angioedema.
\end{abstract}

Keywords Hereditary angioedema $\cdot$ C1-inhibitor $\cdot$ Bradykinin $\cdot$ Contact activation system $\cdot$ Kallikrein/kinin system $\cdot$ Serine protease

\begin{tabular}{|c|c|c|c|}
\hline \multicolumn{2}{|l|}{ Abbreviations } & KKS & Kallikrein/kinin system \\
\hline AA & Attenuated androgens & LTP & Long-term prophylaxis \\
\hline BK & Bradykinin & MASP & Mannose-binding lectin-associated ser- \\
\hline BKRB2 & Bradykinin receptor B2 & & ine protease \\
\hline C1-INH & $\mathrm{C} 1$ esterase inhibitor & nC1-INH-HAE & HAE with normal C1-INH \\
\hline C1-INH-HAE & HAE due to C1-INH deficiency & ODT & On demand therapy \\
\hline EMA & European Medicines Agency & $\mathrm{PKa}$ & Plasma kallikrein \\
\hline FDA & Food and Drug Administration & QoL & Quality of life \\
\hline FFP & Fresh frozen plasma & SERPIN & Serine protease inhibitor \\
\hline FXII & Factor XII & SiRNA & Small interfering RNA \\
\hline FXIIa & Activated factor XII & STP & Short-term prophylaxis \\
\hline
\end{tabular}

Lauré M. Fijen

1.m.fijen@amsterdamumc.nl

1 Department of Vascular Medicine, Amsterdam UMC, University of Amsterdam, Amsterdam, Netherlands

2 Department of Dermatology, University Medical Center, Johannes Gutenberg University, Mainz, Germany

\section{Introduction}

Hereditary angioedema (HAE) is a rare, disabling disorder, with symptoms ranging from disfiguring and incapacitating peripheral swellings, painful abdominal episodes, to potentially fatal laryngeal or oropharyngeal edema [1]. Before the availability of medication and adequate airway 
support, HAE-related mortality was estimated to be as high as 33 to $40 \%$ as a result of asphyxiation [2,3]. For many years, treatment options were limited to fresh frozen plasma (FFP) infusions, antifibrinolytics, progestins, and attenuated androgens (AA). In the past decade various new targeted HAE therapeutics have been developed, with an emphasis on safety, efficacy, and easier routes of administration (including enhanced options for self-administration). Following a brief overview of the pathophysiology of HAE, this paper will review all currently available therapies and new treatment approaches in development for HAE with $\mathrm{C} 1$ esterase inhibitor (C1-INH) deficiency.

\section{Pathophysiology}

HAE is an autosomal dominant inherited disorder. Mutations in SERPING1, the gene that encodes the serine protease inhibitor (SERPIN) C1-INH, account for HAE with C1-INH deficiency (C1-INH-HAE). The two types of C1-INH-HAE, type 1 and type 2, are clinically indistinguishable but are caused by different mutations in the SERPING1 gene. In C1-INH-HAE type 1, the mutations result in truncated or misfolded proteins that are incompletely secreted, leading to decreased plasma levels of $\mathrm{C} 1-\mathrm{INH}$ which are less than $50 \%$, generally 5 to $30 \%$, of normal plasma levels. Mutations causing C1-INH-HAE type 2 are located at exon 8 or near the active site, leading to a fully secreted, but dysfunctional C1-INH protein. Hence, C1-INH functional levels in plasma are decreased in both types, whereas C1-INH antigenic levels are only decreased in C1-INH-HAE type 1 [4]. Other, even more rare, types of HAE are not associated with C1-INH deficiency (HAE with normal C1-INH; nC1-INHHAE, formerly referred to as HAE type 3 ) and include those associated with mutations in the genes expressing factor XII [5], plasminogen [6], angiopoietin-1 [7], kininogen-1 [8], and myoferlin [9]. In one or more remaining types of $\mathrm{nC1}$ INH-HAE, the genetic cause is still unknown. This review will focus on C1-INH-HAE types 1 and 2 as the clinical trials for new HAE therapies are predominantly focusing on these specific types.

C1-INH is a heavily glycosylated single chain SERPIN of 478 amino acid residues. It is the main inhibitor of various complement proteases $(\mathrm{C} 1 \mathrm{r}, \mathrm{C} 1 \mathrm{~s}$, and mannose-binding lectin-associated serine protease; MASP 1 and 2), and contact system proteases (activated factor XII; FXIIa and plasma kallikrein; PKa). In addition, $\mathrm{C} 1-\mathrm{INH}$ is an efficient inhibitor of the intrinsic coagulation pathway (inhibition of activated factors XII and XI) and the fibrinolytic pathway (inhibition of plasmin). If C1-INH levels are decreased or the protein is defective, the kallikrein/kinin system (KKS) is inadequately controlled, leading to excessive release of the nonapeptide bradykinin (BK) which is the predominant mediator of enhanced vascular permeability in angioedema attacks $[10,11]$.

During attacks of C1-INH-HAE, activation of the contact system is initiated by autoactivation of factor XII (FXII), resulting in FXIIa. If uncontrolled by C1-INH FXIIa can activate prekallikrein (PK) to the proteolytic enzyme PKa, which in turn cleaves FXII to produce more FXIIa (see Fig. 1) In addition, the activated PKa liberates BK from high-molecular-weight kininogen (HK) [12, 13]. Once BK ligates the BK B2 receptor (BKRB2) which is constitutively expressed on endothelial cells, nitric oxide is produced leading to simultaneous smooth muscle cell relaxation and transmembrane vascular endothelial cadherin molecule degradation, causing vascular leakage between the endothelial cells $[14,15]$. Moreover, FXIIa, PKa, and BK can activate plasmin from its zymogen plasminogen, thereby activating the fibrinolytic pathway. Plasmin is pivotal for the degradation of cross-linked fibrin. Therefore, plasmin activation results in increased fibrin degradation products including D-dimers that may be increased even in asymptomatic HAE patients. Indeed, D-dimer levels further increase during acute attacks [16]. Plasmin also stimulates the activation of FXII via positive feedback [17]. FXIIa in turn can activate factor XI, thereby initiating the intrinsic coagulation cascade. Nevertheless, HAE is not associated with an increased thrombotic risk.

\section{Historical and Current Prophylactic Treatment}

Treatment of HAE can be divided into two strategies: (1) treatment of acute attacks (on demand therapy; ODT) and (2) prevention of attacks, which includes short-term prophylaxis (STP) and long-term prophylaxis (LTP). It is notable that in the past the decision to initiate LTP used to be solely based on attack frequency, whereas it is nowadays very well recognized that not only burden of disease but also patient preferences should be taken into account [18]. STP is indicated before all procedures that can induce an attack, such as (dental) surgery, endotracheal intubation and endoscopy.

In contrast to angioedema with urticaria, which is predominantly histamine-mediated, antihistamines, corticosteroids, and epinephrine are ineffective in HAE [19]. For LTP, progestins were occasionally used to inhibit the effects of estrogens which may increase FXII, PKa, and HK levels, resulting in (over) consumption of C1-INH [20]. Progestins were reported to have a positive effect on the frequency of angioedema attacks in women with HAE. In most women they are well tolerated, but progestins carry the potential to cause breakthrough vaginal bleeding, pelvic discomfort, and mastalgia [21].

Until the first administration of intravenous plasmaderived C1-INH concentrate in 1979, and its Food and Drug Administration (FDA) approval in 2008, the only 


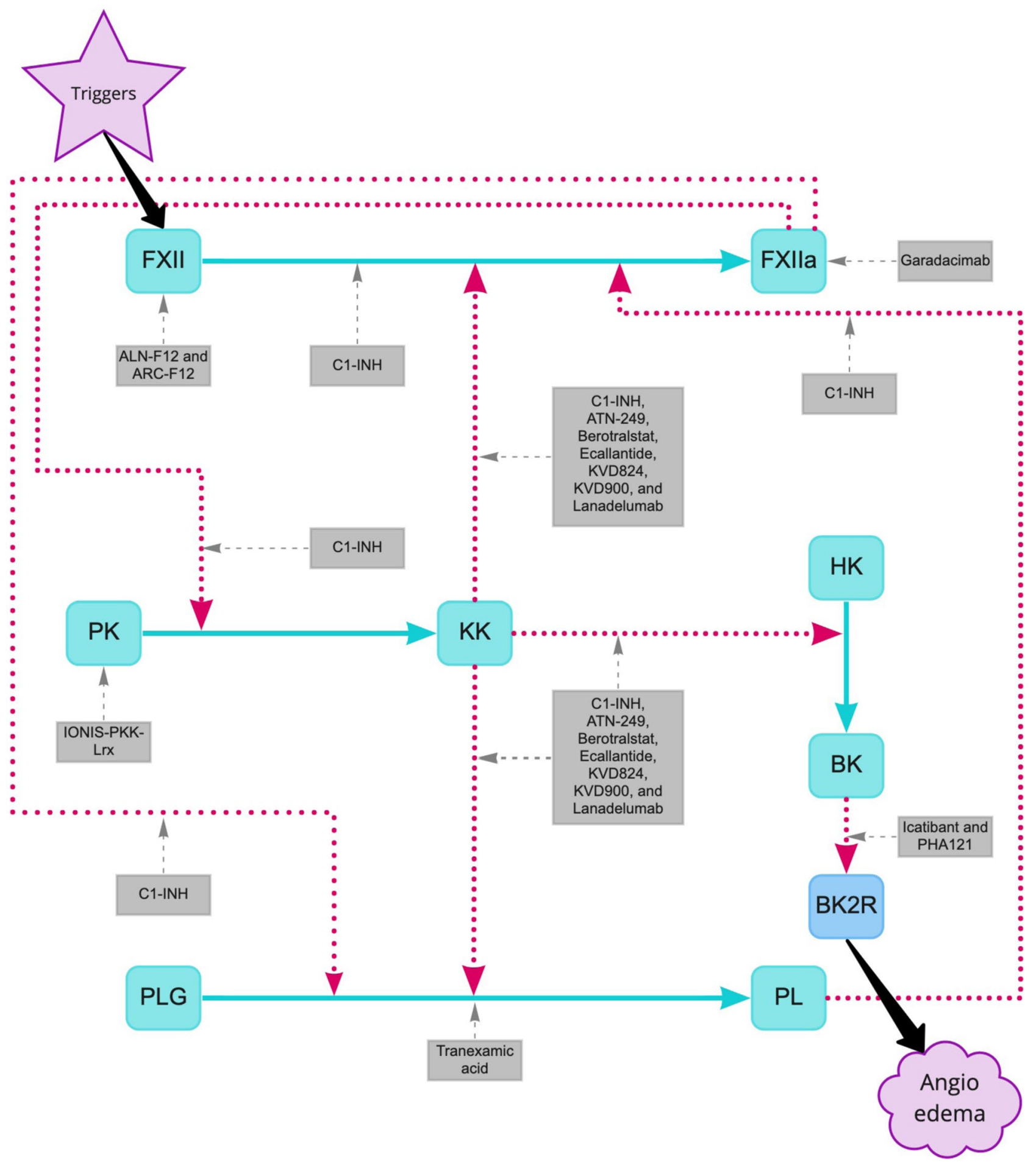

Fig. 1 Pathways inhibited by current HAE drugs and developmental treatment options. Activation of the contact system is initiated by activation of Factor XII (FXII), resulting in activated Factor XII (FXIIa). FXIIa can activate prekallikrein (PK) to plasma kallikrein $(\mathrm{PKa})$, which in turn can activate FXII to produce more FXIIa. In addition, PKa cleaves bradykinin (BK) from high-molecular-weight kininogen (HK). Finally, BK ligates the bradykinin B2 receptor (BKRB2). Additionally, FXIIa and PKa can activate plasmin (PL) from plasminogen (PLG). PL further stimulates the activation of FXII. Activation is indicated by red big-dotted arrows and inhibition by HAE drugs by gray small-dotted arrows. C1-INH denotes $\mathrm{C} 1$ esterase inhibitor 
recommended options for LTP were attenuated androgens (AA) and antifibrinolytics [22, 23].

AA, such as danazol, oxandrolone, and stanozolol, are administered orally. Their mode of action is through induction of C1-INH synthesis in hepatocytes [24] and increased expression of C1-INH mRNA in peripheral blood mononuclear cells [25]. Furthermore, AA induces aminopeptidase P activity, which catabolizes BK [26]. Although AA are effective in a considerable proportion of HAE patients, their long-term use is limited due to a number of potential adverse effects [27]. AA are contraindicated in children and pregnant women (because of their virilising effects), as well as in patients with liver diseases, breast cancer, and prostate cancer [28]. In addition, AA use has been linked to increased cardiovascular risk and hepatocellular carcinoma. To minimize adverse effects, the optimal dose for danazol is $\leq 200 \mathrm{mg}$ per day. AA has been recommended for STP in the past, but C1-INH concentrates are currently considered the pre-procedural prophylaxis of choice. Very frequent use of AA for STP may lead to similar side effects as seen with long-term use. Nevertheless, STP with AA is considered to be safe, even in children. AA are used for five days before until two to three days after the procedure [18] (see Table 1).
Tranexamic acid is an orally available antifibrinolytic agent. The recommended dosage is $30-50 \mathrm{mg} / \mathrm{kg}$ daily, divided in two or three doses to a maximum of six grams per day. This lysine analogue holds a wide range of SERPIN activity, amongst which is the competitive inhibition of plasminogen. Thus, the activation of plasminogen into plasmin is reduced, thereby preventing plasminogen-mediated amplification of FXII activation. In most C1-INH-HAE patients, treatment with tranexamic acid is not sufficiently effective. Current international guidelines on HAE do recommend neither AA nor antifibrinolytics as a first-line therapy [29].

C1-INH concentrates supplement the deficient or replace the dysfunctional C1-INH in HAE patients, thus enabling inhibition of FXIIa and PKa in order to prevent excessive BK production. Plasma-derived $\mathrm{C} 1-\mathrm{INH}$ concentrates (Cinryze ${ }^{\circledR}$ and Berinert ${ }^{\circledR}$ ) are an effective option for both LTP and STP [30-32]. The recommended dosages for STP with plasma-derived C1-INH concentrates are $1000 \mathrm{IU}$ or $20 \mathrm{IU} / \mathrm{kg}$, whereas the recommended LTP dose for Cinryze ${ }^{\circledR}$ is 1000 IU per 3-4 days. Berinert ${ }^{\circledR}$ has not been licensed for LTP. Although intravenous access is required for administration, many patients can be trained for self-administration which was found to be safe

Table 1 Current treatment options for hereditary angioedema with C1-inhibitor deficiency

\begin{tabular}{|c|c|c|c|c|c|}
\hline Drug (trade name) & Manufacturer & Mechanism of action & Indication & Administration & Age indications \\
\hline $\begin{array}{l}\text { Attenuated androgens: } \\
\text { danazol, oxandrolone, } \\
\text { and stanozolol }\end{array}$ & Generic manufacturers & $\begin{array}{l}\text { AA induce aminopepti- } \\
\text { dase P activity and } \\
\text { increase C1-INH } \\
\text { synthesis and C1-INH } \\
\text { mRNA expression }\end{array}$ & LTP, STP & Oral & $\geq 18$ years \\
\hline Berotralstat (Orladeyo®) & $\begin{array}{l}\text { BioCryst Pharmaceu- } \\
\text { ticals }\end{array}$ & Kallikrein inhibitor & LTP & Oral & $\begin{array}{l}\text { FDA: } \geq 12 \text { years, under } \\
\text { review for EMA } \\
\text { approval }\end{array}$ \\
\hline $\begin{array}{l}\text { Plasma-derived C1-INH } \\
\left.\text { (Berinert }{ }^{\circledR}\right)\end{array}$ & CSL Behring & $\begin{array}{l}\text { Plasma-derived C1-INH } \\
\text { concentrate }\end{array}$ & ODT, STP & Intravenous & All \\
\hline $\begin{array}{l}\text { Plasma-derived C1-INH } \\
\left.\text { (Cinryze }{ }^{\circledR}\right)\end{array}$ & Takeda & $\begin{array}{l}\text { Plasma-derived C1-INH } \\
\text { concentrate }\end{array}$ & LTP, ODT, STP & Intravenous & $\begin{array}{l}\text { LTP } \geq 6 \text { years, ODT and } \\
\text { STP } \geq 2 \text { years }\end{array}$ \\
\hline $\begin{array}{l}\text { Conestat alfa (Rucon- } \\
\text { est }(\text { ) }\end{array}$ & Pharming Group NV & $\begin{array}{l}\text { Recombinant } \mathrm{C} 1-\mathrm{INH} \\
\text { concentrate }\end{array}$ & ODT & Intravenous & $\begin{array}{l}\text { FDA: adolescents and } \\
\text { adults EMA: } \geq 2 \text { years }\end{array}$ \\
\hline Ecallantide (Kalbitor®) & Takeda & Kallikrein inhibitor & ODT & $\begin{array}{l}\text { Subcutaneous, no } \\
\text { self-administra- } \\
\text { tion }\end{array}$ & $\geq 12$ years \\
\hline $\begin{array}{l}\text { Plasma-derived C1-INH } \\
\text { (Haegarda®) }\end{array}$ & CSL Behring & $\begin{array}{l}\text { Plasma-derived C1-INH } \\
\text { concentrate }\end{array}$ & LTP & Subcutaneous & $\geq 12$ years \\
\hline Icatibant (Firazyr®) & Takeda & BKRB2 antagonist & ODT & Subcutaneous & $\begin{array}{l}\text { FDA: } \geq 18 \text { years } \\
\text { EMA }: \geq 2 \text { years }\end{array}$ \\
\hline $\begin{array}{l}\text { Lanadelumab } \\
\text { (Takhzyro®) }\end{array}$ & Takeda & Kallikrein inhibitor & LTP & Subcutaneous & $\geq 12$ years \\
\hline $\begin{array}{l}\text { Tranexamic acid } \\
\left(\text { Cyklokapron }{ }^{\circledR}\right)\end{array}$ & Generic manufacturers & $\begin{array}{l}\text { Competitive inhibitor of } \\
\text { plasminogen-mediated } \\
\text { FXII activation }\end{array}$ & LTP & Oral & Adolescents and adults \\
\hline
\end{tabular}

$A A$ attenuated androgens, BKRB2 bradykinin receptor B2, C1-INH C1 esterase inhibitor, LTP long-term prophylaxis, ODT on demand treatment, STP short-term prophylaxis 
and highly effective [33]. It is of note however that longterm venous access may become complicated. Indwelling central catheters have been inserted in a subgroup of these patients, thereby risking serious complications such as thrombotic events and infections [34].

Haegarda ${ }^{\circledR}$ is a new generation of plasma-derived $\mathrm{C} 1-\mathrm{INH}$ concentrate that is administered subcutaneously. It was licensed in 2017 by the FDA for LTP in adolescents and adults. Clinical efficacy was demonstrated in the phase 3 Clinical Studies for Optimal Management in Preventing Angioedema with low-volume subcutaneous C1-inhibitor replacement Therapy (COMPACT) trial, in which a total of $83 \%$ of patients receiving the recommended dose of self-administered $60 \mathrm{IU} / \mathrm{kg}$ twice weekly were free of attacks in the long-term extension arm [35]. Moreover, this treatment improved HAErelated quality of life (QoL) [36].

Lanadelumab (Takhzyro ${ }^{\circledR}$ ) is another subcutaneously administered drug that has been licensed for LTP in patients aged 12 years and older. This fully human IgG1 monoclonal antibody directed against PKa was approved by the FDA in 2018. In the phase 3 Hereditary Angioedema Long-term Prophylaxis (HELP) study, the average breakthrough attack rate was significantly lower in the groups that received $300 \mathrm{mg}$ every 2 weeks and every 4 weeks as compared with placebo (respectively 0.26 and 0.53 versus 1.97 attacks per month) [37]. In addition, $66.7 \%$ of patients receiving $300 \mathrm{mg}$ fortnightly reported a reduction of $\geq 90 \%$ of angioedema attacks during the treatment course of 26 weeks. Achievement of the minimal clinically important difference in total QoLscore was reported across all treatment arms (including $37 \%$ receiving placebo), with the greatest improvement (81\%) shown in the $300 \mathrm{mg}$ every 2 weeks arm which is the currently recommended dose. A tentative prolongation of the dosing interval to once every 4 weeks can be considered once clinical remission is achieved.

The most recent addition to the arsenal of LTP is the oral PKa inhibitor berotralstat (Orladeyo ${ }^{\circledR}$, formerly BCX7353), approved for HAE patients aged 12 years and older by the FDA. The Efficacy and Safety Study of BCX7353 as an Oral Treatment for the Prevention of Attacks in HAE (APeX-2) study, a phase 3, randomized, double-blind, placebo-controlled study showed a $44 \%$ reduction in attack rate compared with placebo [38]. Notably, gastrointestinal side effects occurred frequently across all three study arms ( $42 \%$ in the group that received $110 \mathrm{mg}, 50 \%$ in the $150 \mathrm{mg}$ arm, and up to $36 \%$ in the placebo group) [39]. An open-label long-term safety study assessing the dose of $125 \mathrm{mg}$ once daily is currently being conducted and an application for EMA approval has been submitted [40].

\section{Historical and Current on Demand (acute) Treatment}

Historically, HAE patients were treated with high volumes of fresh-frozen plasma (FFP) for acute attacks, because FFP are easily available and assumed to contain some amount of functional C1-INH from the donor's plasma [41, 42]. Although its benefit has never been objectively established in randomized controlled trials, FFP might be effective provided that large volumes are used. However, FFP bears the risks of transmission of blood borne pathogens and could theoretically exacerbate an HAE attack or escalate its severity, due to plasma kininogens that may provide substrate for additional BK release [43]. Therefore, FFP is only recommended for life-threatening attacks when other ODT options are lacking [29].

Plasma-derived C1-INH concentrates (Cinryze ${ }^{\circledR}$ and Berinert $(\mathbb{B})$ are effective and recommended options for ODT, using $1000 \mathrm{IU}$ of Cinryze ${ }^{\circledR}$ or $20 \mathrm{IU} / \mathrm{kg}$ of Berinert ${ }^{\circledR}$ in children and adults. Although the use of other plasmaderived products (e.g., clotting factor concentrates) has led to the transmission of blood borne viral infections such as human immunodeficiency virus and hepatitis $\mathrm{C}$, the transmission risk has almost completely abated for C1-INH concentrates since the application of nanofiltration. This technique prevents enveloped and non-enveloped viruses and likely even prions from contaminating these plasma products.

In 2017, Shire Pharmaceuticals reported a supply shortage of Cinryze ${ }^{\circledR}$ in many European Union countries and the United States of America (USA) as the demand had exceeded the production capacity. Such shortages can be circumvented with the use of recombinant $\mathrm{C} 1$-INH concentrate conestat alfa (Ruconest $\left.{ }^{\circledR}\right)$ which does not depend on plasma donors and can be produced in large quantities. Conestat alfa is isolated from the milk of transgenic rabbits harbouring genomic human C1-INH sequences. Its glycosylation pattern differs from plasma-derived $\mathrm{C} 1$-INH concentrate, resulting in a lower half-life, due to glycosylation-dependent clearance of C1-INH concentrate in the liver [44]. Currently, conestat alfa is only licensed for ODT, dosed at $50 \mathrm{IU} / \mathrm{kg}$ in patients $<84 \mathrm{~kg}$ or $4200 \mathrm{IU}$ in patients with a body weight of $\geq 84 \mathrm{~kg}$. Despite its lower half-life, conestat alfa has also shown efficacy for STP [45], as well as for LTP [46]. These findings suggest that the treatment effect does not solely depend on plasma concentrations of C1-INH. Theoretically, recombinant $\mathrm{C} 1-\mathrm{INH}$ may be bound to endothelial cells and still be biologically active though undetectable in plasma.

To date, ecallantide (Kalbitor ${ }^{\circledR}$, formerly DX-88) is the only direct PKa inhibitor available for ODT in patients aged 12 years and older (USA only), with a recommended subcutaneous dosage of $30 \mathrm{mg}$ [47]. In the Evaluation of DX-88's Effects in Mitigating Angioedema (EDEMA) 4 trial, a phase 3 , double-blind, 
placebo-controlled randomized trial, ecallantide showed a significant reduction in mean symptom complex severity score and was associated with a significantly larger mean treatment outcome score compared with placebo [48]. Since anaphylaxis was reported in $3.5 \%$ of patients, ecallantide contains a black box warning in the USA and may only be administered by a healthcare professional in a setting with adequate medical support $[49,50]$.

More downstream inhibition of the KKS and the effects of BK on the vessel wall can be achieved with icatibant (Firazyr ${ }^{\circledR}$ ), a synthetic decapeptide which acts as a competitive selective antagonist of the BK2 receptor. The For Angioedema Subcutaneous Treatment (FAST)-3 trial, a randomized, double-blind, placebo-controlled phase 3 study demonstrated a significantly shorter time to onset of symptom relief with icatibant $(2.0 \mathrm{~h})$ than with placebo $(19.8 ; P<0.0001)$ [51]. An important observation in further observational studies was the faster resolution of an angioedema attack when icatibant was administered early compared with late treatment [52]. Icatibant can be self-administered subcutaneously at a 30-mg dose and is licensed for ODT in patients aged 2 years and older by the European Medicines Agency (EMA), although the FDA approved icatibant only in adults.

\section{Future HAE Treatment Strategies}

As long as absolute curation of HAE remains impossible, the development of newer drugs is focusing on increased efficacy, tolerability, and enhanced ease of administration. The newest LTP HAE drugs currently under development are highly specific (targeting a single protein of the KKS or contact system) and are either administered less frequent (once monthly or less) or orally. Likewise, some of the newest ODT drugs in clinical development are administered orally.

Several LTP therapies currently in development are specifically targeting FXII(a), the initiator of the BK-producing pathway. Garadacimab® (formerly CSL312) is the first fully human monoclonal antibody directed against FXIIa. The first clinical trial was initiated in 2017 and analysis of the first randomization period of the phase 2 trial showed an almost $99 \%$ reduction in breakthrough attacks compared with placebo, with a favourable safety profile [53] (see Table 2). Another mode of FXII inhibition is through small interfering RNA (siRNA), a sophisticated technique in which intracellular translation of FXII mRNA into the FXII protein is prevented by $\sim 20-30$ nucleotide RNA molecules. Two siRNAs are in preclinical development: $A L N-F 12 \AA$ and $A R C-F 12 \circledR[54,55]$. Treatment with siRNAs seems

Table 2 Developmental treatments for hereditary angioedema with C1-inhibitor deficiency

\begin{tabular}{|c|c|c|c|c|c|}
\hline Drug (trade name) & Manufacturer & Mechanism of action & Planned indication & Administration & Regulatory status \\
\hline ALN-F12® & $\begin{array}{l}\text { Alnylam Pharmaceu- } \\
\text { ticals }\end{array}$ & $\begin{array}{l}\text { RNA interference tar- } \\
\text { geted at FXII }\end{array}$ & LTP & Subcutaneous & Preclinical development \\
\hline ARC-F12@ & $\begin{array}{l}\text { Arrowhead Pharmaceu- } \\
\text { ticals }\end{array}$ & $\begin{array}{l}\text { RNA interference tar- } \\
\text { geted at FXII }\end{array}$ & LTP & Subcutaneous & Preclinical development \\
\hline ATN-249® & Attune Pharmaceuticals & Kallikrein inhibitor & LTP & Oral & Phase 1 trial is complete \\
\hline Berotralstat (BCX7353) & $\begin{array}{l}\text { BioCryst Pharmaceu- } \\
\text { ticals }\end{array}$ & Kallikrein inhibitor & ODT & Oral & Phase 2 trial is complete \\
\hline BMN 331® & BioMarin & $\begin{array}{l}\text { Adeno-associated virus- } \\
\text { mediated antibody } \\
\text { delivery gene therapy }\end{array}$ & LTP & Intravenous & Preclinical development \\
\hline $\begin{array}{l}\text { Conestat alfa (Rucon- } \\
\left.\text { est( }{ }^{\circledR}\right)\end{array}$ & Pharming Group NV & $\begin{array}{l}\text { Recombinant } \mathrm{C} 1-\mathrm{INH} \\
\text { concentrate }\end{array}$ & LTP & Intravenous & Phase 2 trial is complete \\
\hline Garadacimab® & CSL Behring & $\begin{array}{l}\text { Humanised anti-FXIIa } \\
\text { monoclonal antibody }\end{array}$ & LTP & Subcutaneous & Phase 2 trial is recruiting \\
\hline IONIS-PKK-L ${ }_{\mathrm{Rx}}{ }^{\circledR}$ & IONIS Pharmaceuticals & $\begin{array}{l}\text { Antisense oligonucleo- } \\
\text { tide targeted at prekal- } \\
\text { likrein }\end{array}$ & LTP & Subcutaneous & $\begin{array}{l}\text { Phase } 2 \text { results are } \\
\text { expected Q2 } 2021\end{array}$ \\
\hline KVD824® & $\begin{array}{l}\text { KalVista Pharmaceu- } \\
\text { ticals }\end{array}$ & Kallikrein inhibitor & LTP & Oral & $\begin{array}{l}\text { Phase } 2 \text { trial is expected } \\
\text { to start in } 2021\end{array}$ \\
\hline KVD900® & $\begin{array}{l}\text { KalVista Pharmaceu- } \\
\text { ticals }\end{array}$ & Kallikrein inhibitor & ODT & Oral & $\begin{array}{l}\text { Phase } 2 \text { trial data are } \\
\text { expected in Q1 } 2021\end{array}$ \\
\hline NTLA-2002® & Intellia Therapeutics & $\begin{array}{l}\text { CRISPR/Cas9 editing of } \\
\text { KLKB1 }\end{array}$ & LTP & Intravenous & Preclinical development \\
\hline PHA022121® & Pharvaris & BKRB2 antagonist & LTP, ODT & Oral & Phase 2 trial is in progress \\
\hline
\end{tabular}

$B K R B 2$ bradykinin receptor $\mathrm{B} 2, C 1-I N H \mathrm{C} 1$ esterase inhibitor, LTP long-term prophylaxis, $O D T$ on demand treatment 
promising, as the very long half-lives allow dosing as infrequent as twice annually [56].

More downstream inhibition of the KKS is accomplished by targeting plasma PK. IONIS-PKK- $L_{R x}{ }^{\circledR}$ is a secondgeneration antisense oligonucleotide that can selectively reduce hepatic plasma prekallikrein mRNA synthesis. The phase 1 study with IONIS-PKK- $L_{R x}{ }^{\circledR}$ showed a well-tolerated safety profile with reductions in plasma prekallikrein up to 94\%. In addition, two patients with severe BK-mediated angioedema, including one patient with C1-INH-HAE, have been treated with IONIS-PKK- $L_{R x}{ }^{\circledR}$ under a compassionate use protocol and their attack rate was effectively reduced, with a good tolerability of the drug [57]. A phase 2 trial comparing subcutaneous IONIS-PKK- $L_{R x}{ }^{\circledR} 80 \mathrm{mg}$ once monthly to placebo is ongoing [58]. Another investigational preparation targeting prekallikrein is $N T L A-2002 \circledast$, which is in preclinical development. Intellia Therapeutics has designed this treatment to knockout the $K L K B 1$ gene-encoding plasma PK—using CRISPR/Cas9 technology. Hereby NTLA-2002® aims to prevent the production of prekallikrein long-term through a single course of treatment [59].

Berotralstat, the first approved oral PKa inhibitor for LTP, was investigated in liquid formulation for ODT in the ZENITH- 1 study. This phase 2 trial showed that a single dose of $750 \mathrm{mg}$ reduced symptom severity and use of additional rescue medication, with a favourable safety profile [60]. Three other oral PKa inhibitors under development are $A T N-249 \circledR, K V D 824 \circledR$, and $K V D 900 \circledR[61,62]$. $A T N-249 \circledR$, developed for LTP, has recently successfully completed a phase 1 trial [63]. The results of the phase 2 trial of $K V D 900 \AA$, investigating its effectiveness as ODT, are expected in 2021 [64]. KVD824® has a markedly longer half-life than $K V D 900 \AA$, and therefore, its intended use is LTP. $K V D 824{ }^{\circledR}$ has successfully completed its first-inhuman study and a phase 2 trial is expected to start soon [65].

PHA022121® is the first oral drug (in the form of soft gel capsules) targeted at the BKRB2 receptor for use in acute attacks of HAE (ODT). This is a selective, competitive receptor antagonist that was shown to be highly potent in preclinical studies [66]. The phase 1 trial started in July 2019 and a phase 2 trial is expected to start soon.

Ambitiously, the first gene therapy strategies are already in preclinical development. An adeno-associated virus-mediated antibody delivery gene therapy demonstrated the induction of sustained and adequate plasma levels of C1-INH for at least 24 weeks in a murine model of HAE, by introducing an extrachromosomal copy of SERPING1 into the cells [67]. BioMarin (BMN 331®) [68] and Regenxbio [69] are currently conducting preclinical experiments with these novel adenoassociated virus gene therapies for HAE. The potential longterm protection after a single treatment with such therapies is promising. Naturally, clinical safety and efficacy studies will be necessary before any further conclusions about these new therapeutic strategies can be drawn. Another challenge is the high levels of functional C1-INH levels required to effectively reduce breakthrough attacks [70]. The residual functional C1-INH in most C1-INH-HAE patients is $10-15 \%$, while the minimal amount of C1-INH required to effectively prevent attacks is above $38 \%$ [71]. This contrasts to congenital factor IX deficiency (haemophilia B) for instance, in which only small antigenic increases of factor IX by gene therapy can induce marked reductions in disease severity [72].

\section{Discussion}

This article focused on the current and future therapeutic options for C1-INH-HAE. With the development of highly effective therapies that are more easily administered and cause fewer side-effects than the conventional drugs, treatment decisions for C1-INH-HAE are expected to shift towards more personalized preferences with better disease control, provided that these drugs are affordable and accessible.

Within the last few years, two new LTP options became available and tremendously changed the field of C1-INHHAE treatment. These options concern the subcutaneous C1-INH concentrate and the PKa inhibitor lanadelumab. Both are highly effective in the prevention of breakthrough attacks and showed impressive results, with high proportions of patients experiencing a complete lack of HAE attacks in their respective trials.

The present shift in treatment options will raise new clinical questions. Although the International/Canadian HAE guideline recommends both subcutaneous $\mathrm{C} 1-\mathrm{INH}$ or lanadelumab as first-line therapy [29], adherence to this recommendation may become restricted by the high costs of treatment. It will therefore be essential to determine the indications and identify patients that may benefit the most from this newest generation of treatments. Furthermore, it is currently unknown whether STP prior to invasive procedures remains necessary in patients with well controlled HAE under highly effective LTP. Moreover, once patients require parenteral STP or ODT less often, they might lose their skills to self-administer these drugs. Thus, better disease control could seemingly adversely lead to more emergency department visits by C1-INH-HAE patients, when they require intravenous agents for ODT. In addition, orally administered ODT may pose other drawbacks, such as impaired swallowing during laryngeal or oropharyngeal angioedema attacks, or abdominal attacks (due to vomiting), and a potentially reduced absorption during abdominal attacks. In the latter case, oral drugs may work less rapid than parenteral administered therapies. Nonetheless, oral ODT would certainly shorten the time to administration in patients who are currently dependent on healthcare professionals for the administration of parenteral ODT and in patients with reluctance to injections. 
Another potential unexplored issue concerns the concomitant use of both ODT and LTP with the same mechanism of action. Whether PKa inhibitors developed for ODT will be effective in patients on LTP targeting the same protein remains to be elucidated. Moreover, it is still uncertain whether current limitations for C1-INH-HAE patients, such as the avoidance of estrogen-containing contraceptives, will remain necessary.

Even though the therapeutic options have widely expanded, the number of treatment options remains limited in certain subgroups of patients. For pregnant or breastfeeding patients, as well as children under the age of 12 years, the licensed therapies were virtually unchanged in recent years. This review focused on patients with C1-INH-HAE, since the aforementioned drugs have been primarily investigated in this population. Whether their clinical efficacy is similar in patients with other BK-mediated angioedema (such as nC1-INH-HAE or angiotensin-converting enzyme inhibitor-induced angioedema) needs to be assessed in future trials. Thinking further ahead, the first steps have been made in the domain of gene therapy for C1-INH-HAE. This opens the field for completely novel treatment options.

\section{Conclusion}

Increased insights in the pathophysiology of HAE have paved the way for the development of new and more targeted therapies. The availability of more easily administered ODT options has improved both patients' safety and quality of life. The anticipated shift towards highly effective, less frequently administered, and easily used LTP will hopefully further reduce the frequency and severity of HAE attacks and ameliorate the burden on HAE patients.

Authors' Contributions All authors conceived the presented idea. L.F. performed the literature search and drafted the manuscript. D.C. and K.B critically revised the work. All authors contributed to the final manuscript.

\section{Compliance with Ethical Standards}

Conflicts of Interest K.B. has received grant research support and/or speaker fees from CSL Behring and Shire (a Takeda company), outside the submitted work

D.C. reports consultancy fees from BioCryst, CSL Behring, Pharming, Pharvaris and Shire (a Takeda company), outside the submitted work. L.F. declares no conflict of interest.

Open Access This article is licensed under a Creative Commons Attribution 4.0 International License, which permits use, sharing, adaptation, distribution and reproduction in any medium or format, as long as you give appropriate credit to the original author(s) and the source, provide a link to the Creative Commons licence, and indicate if changes were made. The images or other third party material in this article are included in the article's Creative Commons licence, unless indicated otherwise in a credit line to the material. If material is not included in the article's Creative Commons licence and your intended use is not permitted by statutory regulation or exceeds the permitted use, you will need to obtain permission directly from the copyright holder. To view a copy of this licence, visit http://creativecommons.org/licenses/by/4.0/.

\section{References}

1. Bork K, Meng G, Staubach P, Hardt J (2006) Hereditary angioedema: new findings concerning symptoms, affected organs, and course. Am J Med 119(3):267-274. https://doi. org/10.1016/j.amjmed.2005.09.064

2. Bork K, Hardt J, Witzke G (2012) Fatal laryngeal attacks and mortality in hereditary angioedema due to C1-INH deficiency. J Allergy Clin Immunol 130(3):692-697. https:// doi.org/10.1016/j.jaci.2012.05.055

3. Bork K, Siedlecki K, Bosch S, Schopf RE, Kreuz W (2000) Asphyxiation by laryngeal edema in patients with hereditary angioedema. Mayo Clin Proc 75(4):349-354. https://doi. org/10.4065/75.4.349

4. Cicardi M, Aberer W, Banerji A, Bas M, Bernstein JA, Bork $\mathrm{K}$ et al (2014) Classification, diagnosis, and approach to treatment for angioedema: consensus report from the Hereditary Angioedema International Working Group. Allergy 69(5):602616. https://doi.org/10.1111/all.12380

5. Dewald G, Bork K (2006) Missense mutations in the coagulation factor XII (Hageman factor) gene in hereditary angioedema with normal $\mathrm{C} 1$ inhibitor. Biochem Biophys Res Commun 343(4):1286-1289. https://doi.org/10.1016/j.bbrc.2006.03.092

6. Bork K, Wulff K, Steinmuller-Magin L, Braenne I, StaubachRenz P, Witzke G et al (2018) Hereditary angioedema with a mutation in the plasminogen gene. Allergy 73(2):442-450. https://doi.org/10.1111/all.13270

7. Bafunno V, Firinu D, D'Apolito M, Cordisco G, Loffredo S, Leccese A et al (2018) Mutation of the angiopoietin-1 gene (ANGPT1) associates with a new type of hereditary angioedema. J Allergy Clin Immunol 141(3):1009-1017. https://doi.org/10.1016/j.jaci.2017.05.020

8. Bork K, Wulff K, Rossmann H, Steinmuller-Magin L, Braenne I, Witzke G et al (2019) Hereditary angioedema cosegregating with a novel kininogen 1 gene mutation changing the $\mathrm{N}$-terminal cleavage site of bradykinin. Allergy 74(12):2479-2481. https:// doi.org/10.1111/all.13869

9. Ariano A, D'Apolito M, Bova M, Bellanti F, Loffredo S, D'Andrea $G$ et al (2020) A myoferlin gain-of-function variant associates with a new type of hereditary angioedema. Allergy. https://doi.org/10.1111/all.14454

10. Zeerleder S (2011) C1-inhibitor: more than a serine protease inhibitor. Semin Thromb Hemost 37(4):362-374. https://doi. org/10.1055/s-0031-1276585

11. Schmaier AH (2016) The contact activation and kallikrein/kinin systems: pathophysiologic and physiologic activities. J Thromb Haemost 14(1):28-39. https://doi.org/10.1111/jth.13194

12. Colman RW (1984) Surface-mediated defense reactions. The plasma contact activation system. J Clin Invest, 73(5), 1249_ 1253. https://doi.org/10.1172/jci111326

13. Kaplan AP, Joseph K (2014) Pathogenic mechanisms of bradykinin mediated diseases: dysregulation of an innate inflammatory pathway. Adv Immunol 121:41-89. https://doi. org/10.1016/b978-0-12-800100-4.00002-7

14. Zuraw BL, Christiansen SC (2016) HAE pathophysiology and underlying mechanisms. Clin Rev Allergy Immunol 51(2):216229. https://doi.org/10.1007/s12016-016-8561-8 
15. Campbell DJ (2001) The kallikrein-kinin system in humans. Clin Exp Pharmacol Physiol 28(12):1060-1065. https://doi.org/10. 1046/j.1440-1681.2001.03564.x

16. Cugno M, Zanichelli A, Bellatorre AG, Griffini S, Cicardi M (2009) Plasma biomarkers of acute attacks in patients with angioedema due to C1-inhibitor deficiency. Allergy 64(2):254257. https://doi.org/10.1111/j.1398-9995.2008.01859.x

17. Parsopoulou F, Charignon D, Tengo M, Psarros F, Maas C, Gonzalez-Quevedo T, et al (2020) Plasminogen glycoforms alteration and activation susceptibility associated with the missense variant p.Lys330Glu in HAE-PLG patients. Allergy. https://doi. org/10.1111/all.14280

18. Maurer M, Magerl M, Ansotegui I, Aygoren-Pursun E, Betschel $\mathrm{S}$, Bork K et al (2018) The international WAO/EAACI guideline for the management of hereditary angioedema-The 2017 revision and update. Allergy. https://doi.org/10.1111/all.13384

19. Agostoni A, Aygoren-Pursun E, Binkley KE, Blanch A, Bork $\mathrm{K}$, Bouillet L et al (2004) Hereditary and acquired angioedema: problems and progress: proceedings of the third $\mathrm{C} 1$ esterase inhibitor deficiency workshop and beyond. J Allergy Clin Immunol 114(3 Suppl):S51-131. https://doi.org/10.1016/j.jaci.2004.06.047

20. Hoem NO, Johannesen S, Hauge G, Rud AC, Sandem S, Briseid K (1991) Contact activation factors in plasma from women using oral contraceptives-increased levels of factor XII, kinin-free high molecular weight kininogen and acetone-activated kallikrein. Thromb Res 64(4):427-434. https://doi.org/10.1016/00493848(91)90343-u

21. Caballero T, Farkas H, Bouillet L, Bowen T, Gompel A, Fagerberg $\mathrm{C}$ et al (2012) International consensus and practical guidelines on the gynecologic and obstetric management of female patients with hereditary angioedema caused by $\mathrm{C} 1$ inhibitor deficiency. J Allergy Clin Immunol 129(2):308-320. https://doi.org/10.1016/j. jaci.2011.11.025

22. Bork K, Witzke G (1989) Long-term prophylaxis with C1-inhibitor $(\mathrm{C} 1 \mathrm{INH})$ concentrate in patients with recurrent angioedema caused by hereditary and acquired C1-inhibitor deficiency. J Allergy Clin Immunol 83(3):677-682. https://doi.org/10.1016/00916749(89)90082-1

23. Kaplan AP, Pawaskar D, Chiao J (2020) C1 inhibitor activity and angioedema attacks in patients with hereditary angioedema. J Allergy Clin Immunol Pract 8(3):892-900. https://doi. org/10.1016/j.jaip.2019.10.003

24. Birjmohun RS, Kees Hovingh G, Stroes ES, Hofstra JJ, DallingaThie GM, Meijers JC et al (2008) Effects of short-term and long-term danazol treatment on lipoproteins, coagulation, and progression of atherosclerosis: two clinical trials in healthy volunteers and patients with hereditary angioedema. Clin Ther 30(12):2314-2323. https://doi.org/10.1016/j.clinthera.2008.12.021

25. Pappalardo E, Zingale LC, Cicardi M (2003) Increased expression of C1-inhibitor mRNA in patients with hereditary angioedema treated with Danazol. Immunol Lett 86(3):271-276. https://doi. org/10.1016/s0165-2478(03)00029-4

26. Drouet C, Desormeaux A, Robillard J, Ponard D, Bouillet L, Martin L et al (2008) Metallopeptidase activities in hereditary angioedema: effect of androgen prophylaxis on plasma aminopeptidase P. J Allergy Clin Immunol 121(2):429-433. https://doi.org/10.1016/j.jaci.2007.10.048

27. Bork K, Bygum A, Hardt J (2008) Benefits and risks of danazol in hereditary angioedema: a long-term survey of 118 patients. Ann Allergy Asthma Immunol 100(2):153-161. https://doi. org/10.1016/s1081-1206(10)60424-3

28. Lumry WR (2018) Current and emerging therapies to prevent hereditary angioedema attacks. Am J Manag Care 24(14 Suppl):S299-s307

29. Betschel S, Badiou J, Binkley K, Borici-Mazi R, Hebert J, Kanani A et al (2019) The International/Canadian Hereditary Angioedema
Guideline. Allergy Asthma Clin Immunol 15:72. https://doi. org/10.1186/s13223-019-0376-8

30. Craig T, Shapiro R, Vegh A, Baker JW, Bernstein JA, Busse P et al (2017) Efficacy and safety of an intravenous C1-inhibitor concentrate for long-term prophylaxis in hereditary angioedema. Allergy Rhinol (Providence) 8(1):13-19. https://doi.org/10.2500/ ar.2017.8.0192

31. Gavigan G, Yang WH, Santucci S, Harrison R, Karsh J (2014) The prophylactic use of $\mathrm{C} 1$ inhibitor in hereditary angioedema patients undergoing invasive surgical procedures: a retrospective study. Allergy Asthma Clin Immunol 10(1):17. https://doi. org/10.1186/1710-1492-10-17

32. Bork K, Hardt J, Staubach-Renz P, Witzke G (2011) Risk of laryngeal edema and facial swellings after tooth extraction in patients with hereditary angioedema with and without prophylaxis with $\mathrm{C} 1$ inhibitor concentrate: a retrospective study. Oral Surg Oral Med Oral Pathol Oral Radiol Endod 112(1):58 64. https://doi.org/10.1016/j.tripleo.2011.02.034

33. Levi M, Choi G, Picavet C, Hack CE (2006) Self-administration of $\mathrm{C} 1$-inhibitor concentrate in patients with hereditary or acquired angioedema caused by $\mathrm{C} 1$-inhibitor deficiency. $\mathrm{J}$ Allergy Clin Immunol 117(4):904-908. https://doi.org/10.1016/j. jaci.2006.01.002

34. Riedl MA, Bygum A, Lumry W, Magerl M, Bernstein JA, Busse $P$ et al (2016) Safety and usage of C1-inhibitor in hereditary angioedema: Berinert Registry Data. J Allergy Clin Immunol Pract 4(5):963-971. https://doi.org/10.1016/j.jaip.2016.04.018

35. Craig T, Zuraw B, Longhurst H, Cicardi M, Bork K, Grattan C et al (2019) Long-term outcomes with subcutaneous C1-inhibitor replacement therapy for prevention of hereditary angioedema attacks. J Allergy Clin Immunol Pract 7(6):1793-1802.e1792. https://doi.org/10.1016/j.jaip.2019.01.054

36. Lumry WR, Craig T, Zuraw B, Longhurst H, Baker J, Li HH et al (2018) Health-related quality of life with subcutaneous C1-inhibitor for prevention of attacks of hereditary angioedema. J Allergy Clin Immunol Pract 6(5):1733-1741.e1733. https://doi. org/10.1016/j.jaip.2017.12.039

37. Banerji A, Riedl MA, Bernstein JA, Cicardi M, Longhurst HJ, Zuraw BL et al (2018) Effect of lanadelumab compared with placebo on prevention of hereditary angioedema attacks: a randomized clinical trial. JAMA 320(20):2108-2121. https:// doi.org/10.1001/jama.2018.16773

38. Zuraw B, Lumry WR, Johnston DT, Aygören-Pürsün E, Banerji A, Bernstein JA et al (2020) Oral once-daily berotralstat for the prevention of hereditary angioedema attacks: a randomized, double-blind, placebo-controlled phase 3 trial. J Allergy Clin Immunol. https://doi.org/10.1016/j.jaci.2020.10.015

39. Riedl M, Lumry W, Banerji A, Aygoren-Pursun E, Bernstein J, Maurer M et al (2019) P154 safety and tolerability of oncedaily oral kallikrein inhibitor BCX7353 in Phase 3 APEX-2 HAE study. Ann Allergy Asthma Immunol 123(5):S28-S29. https:// doi.org/10.1016/j.anai.2019.08.258

40 U. S. National Library of Medicine. (2018, 2019 Dec 23). A long term safety study of BCX7353 in hereditary angioedema (APeX-S). Retrieved from https://clinicaltrials.gov/ct2/show/ NCT03472040?term $=$ bcx 7353\&draw $=2 \&$ rank $=1$

41. Jaffe CJ, Atkinson JP, Gelfand JA, Frank MM (1975) Hereditary angioedema: the use of fresh frozen plasma for prophylaxis in patients undergoing oral surgery. J Allergy Clin Immunol 55(6):386-393. https://doi.org/10.1016/0091-6749(75)90077-9

42. Pickering RJ, Good RA, Kelly JR, \& Gewurz H (1969) Replacement therapy in hereditary angioedema. Successful treatment of two patients with fresh frozen plasma. Lancet, 1(7590), 326-330. https://doi.org/10.1016/s0140-6736(69)91295-1

43. Zuraw BL (2008) Clinical practice. Hereditary angioedema N Engl J Med 359(10):1027-1036. https://doi.org/10.1056/NEJMcp0803977 
44. Koles K, van Berkel PH, Pieper FR, Nuijens JH, Mannesse ML, Vliegenthart JF et al (2004) N- and O-glycans of recombinant human $\mathrm{C} 1$ inhibitor expressed in the milk of transgenic rabbits. Glycobiology 14(1):51-64. https://doi.org/10.1093/glycob/cwh010

45. Valerieva A, Staevska M, Jesenak M, Hrubiskova K, Sobotkova M, Zachova R et al (2020) Recombinant human C1 esterase inhibitor as short-term prophylaxis in patients with hereditary angioedema. J Allergy Clin Immunol Pract 8(2):799-802. https://doi.org/10.1016/j.jaip.2019.08.011

46. Riedl MA, Grivcheva-Panovska V, Moldovan D, Baker J, Yang WH, Giannetti BM et al (2017) Recombinant human C1 esterase inhibitor for prophylaxis of hereditary angio-oedema: a phase 2, multicentre, randomised, double-blind, placebo-controlled crossover trial. Lancet 390(10102):1595-1602. https://doi. org/10.1016/s0140-6736(17)31963-3

47. Cicardi M, Levy RJ, McNeil DL, Li HH, Sheffer AL, Campion $M$ et al (2010) Ecallantide for the treatment of acute attacks in hereditary angioedema. N Engl J Med 363(6):523-531. https:// doi.org/10.1056/NEJMoa0905079

48. Levy RJ, Lumry WR, McNeil DL, Li HH, Campion M, Horn PT et al (2010) EDEMA4: a phase 3, double-blind study of subcutaneous ecallantide treatment for acute attacks of hereditary angioedema. Ann Allergy Asthma Immunol 104(6):523-529. https://doi.org/10.1016/j.anai.2010.04.012

49. Craig TJ, Li HH, Riedl M, Bernstein JA, Lumry WR, MacGinnitie AJ et al (2015) Characterization of anaphylaxis after ecallantide treatment of hereditary angioedema attacks. J Allergy Clin Immunol Pract 3(2):206-212.e204. https://doi. org/10.1016/j.jaip.2014.09.001

50. Duffey H, Firszt R (2015) Management of acute attacks of hereditary angioedema: role of ecallantide. J Blood Med 6:115123. https://doi.org/10.2147/jbm.S66825

51. Lumry WR, Li HH, Levy RJ, Potter PC, Farkas H, Moldovan $\mathrm{D}$ et al (2011) Randomized placebo-controlled trial of the bradykinin $\mathrm{B}(2)$ receptor antagonist icatibant for the treatment of acute attacks of hereditary angioedema: the FAST- 3 trial. Ann Allergy Asthma Immunol 107(6):529-537. https://doi. org/10.1016/j.anai.2011.08.015

52. Maurer M, Aberer W, Bouillet L, Caballero T, Fabien V, Kanny $G$ et al (2013) Hereditary angioedema attacks resolve faster and are shorter after early icatibant treatment. PLoS ONE 8(2):e53773. https://doi.org/10.1371/journal.pone.0053773

53. Cohn DM, Zuraw BL, Craig T, Bork K, Feuersenger H, Jacobs I, et al A multicenter, randomized, double-blind, dose-ranging phase 2 study investigating the efficacy, pharmacokinetics and safety of prophylaxis with the anti-factor XIIa monoclonal antibody garadacimab in patients with hereditary angioedema [Conference presentation]. Paper presented at the HAE Global Conference 2020. https://haei.org/gc2020/\#scientific

54. Liu J, Qin J, Borodovsky A, Racie T, Castoreno A, Schlegel M et al (2019) An investigational RNAi therapeutic targeting Factor XII (ALN-F12) for the treatment of hereditary angioedema. RNA 25(2):255-263. https://doi.org/10.1261/rna.068916.118

55. Arrowhead Pharmaceuticals. (2016). Arrowhead pharmaceuticals presents new data on ARC-F12 and ARCLPA using DPCsqTM subcutaneous RNAi delivery vehicle. Retrieved from http://ir.arrowheadpharma.com/newsreleases/news-release-details/arrowhead-pharmaceuticalspresents-new-data-arc-f12-and-arc-lpa

56. Ray KK, Wright RS, Kallend D, Koenig W, Leiter LA, Raal FJ et al (2020) Two phase 3 trials of inclisiran in patients with elevated LDL cholesterol. N Engl J Med 382(16):1507-1519. https://doi.org/10.1056/NEJMoa1912387

57. Cohn DM, Viney NJ, Fijen LM, Schneider E, Alexander VJ, Xia $S$ et al (2020) Antisense inhibition of prekallikrein to control hereditary angioedema. N Engl J Med 383(13):1242-1247. https://doi.org/10.1056/NEJMoa1915035

58 U. S. National Library of Medicine. (2020, February 20, 2020). A study to assess the clinical efficacy of IONIS-PKKLRx in participants with hereditary angioedema. Retrieved from https://clinicaltrials.gov/ct2/show/NCT04030598?term= ionis-pkk-lrx\&draw $=2$

59. Intellia Therapeutics. (2020). In vivo therapies. Retrieved from https://www.intelliatx.com/in-vivo-therapies/

60. Longhurst H, Moldovan D, Bygum A, Cicardi M, Huissoon A, Aygoren-Pursun E, et al (2019) Oral plasma kallikrein inhibitor BCX7353 is safe and effective as an on-demand treatment of angioedema attacks in hereditary angioedema (HAE) patients: results of the ZENITH-1 Trial. Paper presented at the AAAAI, San Francisco CA. https://ir.biocryst.com/static-files/2b3e13b9-ad24432c-9ac5-15711d954d88

61. Kalfus I, McDonald A, Qian S (2017) Potency, selectivity, and exposure evaluation of ATN-249, a new oral kallikrein inhibitor for hereditary angioedema. J Allergy Clin Immunol, 139(2), AB378. https://doi.org/10.1016/j.jaci.2016.12.905

62. Hampton SL, De Donatis GM, Murugesan NI, Rushbrooke LJ, Li L, Duckworth E, et al (2019) KVD900 as a single dose, rapid, oral plasma kallikrein inhibitor for the on-demand treatment of hereditary angioedema attacks: pharmacokinetic and pharmacodynamic results from a phase 1 single ascending dose study. Journal of Allergy and Clinical Immunology, 143(2), AB39. https://doi.org/10.1016/j.jaci.2018.12.118

63. Attune Pharmaceuticals. (2019, 2019 Jan 24). Pharmacokinetics and safety of ATN-249, a novel oral plasma kallikrein inhibitor for hereditary angioedema. Retrieved from http://attunepharma.com/ assets/Attune-WSAAI-Poster-Jan-2019.pdf

64 U. S. National Library of Medicine. (2019, 2020 Feb 28). A phase II, cross-over clinical trial evaluating the efficacy and safety of KVD900 in the on-demand treatment of angioedema attacks in adult subjects with hereditary angioedema type I or II. Retrieved from https://clinicaltrials.gov/ct2/show/ NCT04208412?term $=$ kvd900\&draw $=2 \&$ rank $=1$

65. KalVista. (2020). KalVista for HAE. Retrieved from https:// www.kalvista.com/products-pipeline/kalvista-hae

66. Pharvaris. (2020). HAE. Retrieved from https://pharvaris.com/science/

67. Qiu T, Chiuchiolo MJ, Whaley AS, Russo AR, Sondhi D, Kaminsky SM et al (2019) Gene therapy for C1 esterase inhibitor deficiency in a murine model of hereditary angioedema. Allergy 74(6):1081-1089. https://doi.org/10.1111/all.13582

68. BioMarin. (2019, 2019 Nov 14). Poised for significant growth and profitability, biomarin shares company highlights during R\&D day on November 14th in New York. Retrieved from https://investors. biomarin.com/2019-11-14-Poised-for-Significant-Growth-andProfitability-BioMarin-Shares-Company-Highlights-During-R-DDay-on-November-14th-in-New-York

69. Regenxbio. (2019, 2019 Jul 24). Regenxbio expands pipeline using NAV vectors to deliver therapeutic antibodies for the treatment of hereditary angioedema and neurodegenerative diseases. Retrieved from http://ir.regenxbio.com/news-releases/news-release-details/ regenxbio-expands-pipeline-using-nav-vectors-deliver-therapeutic/

70. Zhang Y, Tortorici MA, Pawaskar D, Pragst I, Machnig $\mathrm{T}$, Hutmacher $\mathrm{M}$ et al (2018) Exposure-response model of subcutaneous $\mathrm{C} 1$-inhibitor concentrate to estimate the risk of attacks in patients with hereditary angioedema. CPT Pharmacometrics Syst Pharmacol 7(3):158-165. https://doi. org/10.1002/psp4.12271

71. Späth PJ, Wüthrich B, Bütler R (1984) Quantification of C1-inhibitor functional activities by immunodiffusion assay in plasma of patients with hereditary angioedema-evidence of a functionally critical level of $\mathrm{C} 1$-inhibitor concentration. Complement 1(3):147-159. https://doi.org/10.1159/000467830 
72. Miesbach W, Meijer K, Coppens M, Kampmann P, Klamroth R, Schutgens R et al (2018) Gene therapy with adeno-associated virus vector 5-human factor IX in adults with hemophilia B. Blood 131(9):1022-1031. https://doi.org/10.1182/blood-201709-804419
Publisher's Note Springer Nature remains neutral with regard to jurisdictional claims in published maps and institutional affiliations. 